\title{
Modified quantitative estimation model of erosion and degradation in three mountainous watersheds
}

\author{
D. Emmanouloudis ${ }^{1} \&$ M. Kaikis ${ }^{2}$ \\ ${ }^{I}$ Department of Forestry and Natural Environment Management \\ Technological Educational Institute of Kavala, Annex Drama, Drama, \\ Greece \\ ${ }^{2}$ Rhodes Municipal Environmental Organisation
}

\begin{abstract}
This paper presents a new version of a well-known stochastic model to quantitatively assess drainage basin degradation in order to determine erosion in three torrent basins. This new version, 3D-structured and using G.I.S. for data processing, can provide a quantitative assessment of the degradation of any torrent basin in a very short time. Furthermore, a system to prevent erosion and degradation by means of agricultural and technical forest works is presented; the system was originally designed for these three basins, but it is flexible and easy to adapt to any torrent basin.
\end{abstract}

Keywords: stochastic model, GIS, degradation, 3D Digital Elevation Model.

\section{Introduction}

Drainage basin erosion and degradation is one of the most complex environmental problems worldwide. Thus, it has naturally been the subject of research for many decades in countries representative of all the main climatic types on the planet. The problem is fairly aggravated in the Mediterranean countries, due to their temperature range and other factors (irregularly distributed rainfall, insufficient plant coverage, etc.). In our country, plagued by forest fires in the past decades, it tends to acquire the dimensions of a real disaster for mountainous areas, due to the degradation of the soil it implies. 
The assessment of mountainous soil degradation due to the erosive action of rainwater runoff is of two types:

a) Qualitative assessment (intensity, degree, speed, etc.)

b) Quantitative assessment, usually calculated in total $\mathrm{m} /$ year/basin, or in $\mathrm{m} /$ year/Km, or finally in $\mathrm{mm} / \mathrm{year} / \mathrm{basin}$.

Quantitative assessment is more difficult than the qualitative one, since it implies an attempt at calculating magnitudes and volumes which are hardly measurable in practice and are related to a diachronic effect. In the past few years several methods have been developed for the quantitative assessment of degradation.

The more known methods are referred to be the USLE, WEPP, AGNPS1 [1], CREAMS, ANSWERS [2], EPIC, the method of Rydgren [3] and Terry [4], and the method of Mitas et al. [5], as well as the contemplative methods of Fournier, Corbel and Gavrilovic. The most of them have been used mostly in United States and less in Europe.

However, according to Kotoulas [6] the main feature of these methods is that "they require the existence of basic data which however can not be often designated precisely so that the precision and the potential of their application are reduced". Therefore, according to the same author "the methods being developed to date are far from the point to provide precise and reliable forecasts". Moreover, in the chapter of erosion-degradation this is not the only difficulty. There is questioning even on how to confront the phenomenon particularly in situations during which we have intensive procedures (e.g. after a fire).

In the present paperwork one from the above mentioned methods was selected, the stochastic Gavrilovic [7] model, by the help of which effort was made to estimate the degradation in the selected under research area. This estimation was conducted by the help of specific G.I.S. software (GRASS), which has helped out to simplify the model application on one hand and to increase the precision of the results to an impressive way on the other. After the estimation of degradation was implemented, the quotation of a protection and how to handle a problem was attempted, by applying a system easy-to-use, flexible and particularly effective, as proved by the experience gained to date.

\section{Research area}

As research area was selected the broader area of Kastoria Prefecture and especially four small torrential watersheds from which two were directly adjacent. As a reason of the above selection is quoted the fact that the aforesaid area -because of its geomorphologic condition- has many, in direct or less direct proximity, small runoff basins which particularly show a special vegetative and geological diversity.

Of course, it is easily comprehensible why a model, in order to be elaborated, requires watersheds of small size. Regarding the highest possible proximity, an identification of the attack climatic factors in all parts of the sample is essential, so that the results obtained by the research are directly comparative. Following these thoughts we selected the above stated sample of four watersheds. 


\section{Research method}

The morphometric characteristics of the selected watersheds have led us necessarily (because the so called method provides particularly good results when estimating the degradation in small basins of mountainous areas Gavrilovic [7], Pintar [9], Kotoulas [6]), to the selection of the Gavrilovic method. This method is uniquely appropriate to estimate the degradation in small mountainous watersheds, as the ones included in our sample.

In Table 1 the morphometric characteristics of the sample watersheds are quoted, which define the mountainous character of the specific torrents.

Table 1: Morphometric characteristics of the sample watersheds.

\begin{tabular}{|l|l|c|r|c|c|}
\hline \multirow{2}{*}{ No } & \multirow{2}{*}{ Torrents } & \multicolumn{2}{|c|}{$\mathrm{F}_{\text {wat }}\left(\mathrm{Km}^{2}\right)$} & $\mathrm{H}_{\max }(\mathrm{m})$ & $\mathrm{J}_{\mathrm{mW}}(\%)$ \\
\cline { 3 - 6 } & Projective & $3 \mathrm{D}^{\prime \prime}$ & $\begin{array}{c}(\mathrm{max} \\
\text { elevation })\end{array}$ & $\begin{array}{c}\text { (mean watershed } \\
\text { slope) }\end{array}$ \\
\hline 1 & Riganorema & 9.43 & 10.03 & 1420 & 30.90 \\
\hline 2 & Fotini & 4.23 & 4.46 & 1190 & 29.41 \\
\hline 3 & Triantafillia & 8.42 & 8.98 & 1580 & 33.32 \\
\hline
\end{tabular}

$\mathrm{F}_{3 \mathrm{D}}$ stands for the watershed area, not as it results from the calculation on the map $\left(\mathrm{F}_{\mathrm{PR} 0 \mathrm{~J}}\right)$ but for the actual area of the basin in three-dimensional format, as it results from the calculation after a $3 \mathrm{D}$ construction of the watershed by the help of GRASS. The $F_{3 D}$ is slightly bigger than $F_{P E 0 J}$ and the deviation from each other depends on the average surface slope of the watershed, Emmanouloudis and Filippidis [10].

The above data was obtained from maps 1:50.000 of the G.A.S. (Sheets KASTORIA, MESOPOTAMIA).

According to the Gavrilovic method eqn (1), the type providing the average annual degradation in a watershed is:

$$
W=T \cdot h \cdot \pi \cdot \sqrt{z^{3}} \cdot F
$$

where $\mathrm{T}$, eqn (2), is coefficient of temperature given by the type:

$$
T=\sqrt{\frac{t_{0}}{10}+0,1}
$$

with $t_{0}$ : average annual temperature in the watershed

$\mathrm{h}$ : average annual height of rain $(\mathrm{mm})$

$\pi: 3.14$

F: area of watershed $\left(\mathrm{Km}^{2}\right)$ and

$\mathrm{z}$ : coefficient of erosion given by the ratio $z=x \cdot y \cdot(\varphi+\sqrt{J})$

with $\chi, \mathrm{y}, \varphi$ being the partial coefficients that depend on the vegetation, the geological base and the erosion degree of the watershed respectively whereas $j$ is the average slope of the watershed area expressed as angle tangent.

It is implied that the values of $\chi, \mathrm{y}$, and $\varphi$ are given analytically in tables by Gavrilovic. The selections of the suitable values assigned to each case are at the 
aptitude of the researcher who applies the formula when needed. By applying the method, each watershed under research was divided by the authors in spots depending on:

- the vegetation species prevailing in each part

- the geological base it was consisted of

- the seats of producing debris material.

Therefore, for example, there could be 6 vegetation spots distributed as follows: 2 spots of forest, 1 spot with shrubby plants, 1 spot with pastures, 2 spots with arid lands. There could also be 4 spots of geological base, 2 of them having geological base of granite, one gneiss and the other schist and so on. It is implied that the spots of vegetation, geology, seats of producing debris material are not identical as far as their boundaries are concerned.

Given that often the spots of vegetation, geology, etc., were numerous, it becomes clear that this method was knotty, time-consuming and not particularly accurate, because the Gavrilovic method functions by the same slope for the whole watershed.

To overcome this insufficiency, we stretched further the Gavrilovic model by improving the ways of spot separation. The G.I.S. GRASS [11] served greatly this effort. The following methodology was applied:

In sheets of the G.A.S., the research area was scanned on GIS layers and converted to image with the use of image processing software.

Then, converted into an appropriate image file format readable by GRASS, the scanned area was imported in GRASS in raster image format.

Image rectification or registration of the research area was the next processing step. The rectification was originally carried out by digitization of 4 points, that is 4 angles, of the area on the HATT grid, and then by conversion of the raster co-ordinates imported in GRASS (which were in accordance to a local reference system) into projectional co-ordinates, with the use of linear affine transformation.

Then, using the scanned rectified map, the research area was digitized [12] more specifically, digitization involved basin frontiers, peaks and contours (for peaks and contours the relevant elevation data were provided). Following this, the spots of vegetation, geology and erodibility were digitized, as suggested by the Gavrilovic formula on the basis of its $\mathrm{x}, \mathrm{y}$ and (p. These spots were numbered and their respective values were provided according to the Gavrilovic tables. Following the above processing, all the data were exported in vector format and, after topology building, were converted in raster format, in view of producing all necessary maps and proceed to the necessary calculations.

More specifically, from the 3 raster of the contours, the Digital Elevation Models (DEM) were produced, 3D-views of which can be seen on figures 1,2 and 3 .

Then, on the basis of these Digital Elevation Models, the slope maps were created. In order for the DEMs to be accurate, the very same slopes were used, which of course differed for every cell of the slope raster, i.e. an area of approx. $67 \mathrm{~m}(8.17 \mathrm{~m} \mathrm{X} \mathrm{8.18m)} \mathrm{for} \mathrm{the} \mathrm{torrents} \mathrm{of} \mathrm{Fotini} \mathrm{and} \mathrm{Riganorema} \mathrm{and} 36 \mathrm{~m} 2(6 \mathrm{~m}$ $\mathrm{X} 6 \mathrm{~m}$ ) for the torrent of Triantafillia. 


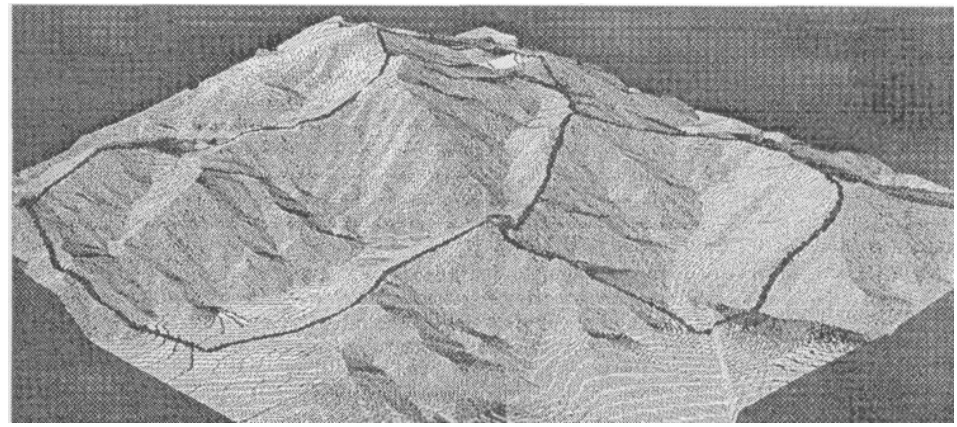

Figure 1: $\quad 3 \mathrm{D}$ View of watersheds Riganorema and Fotini.

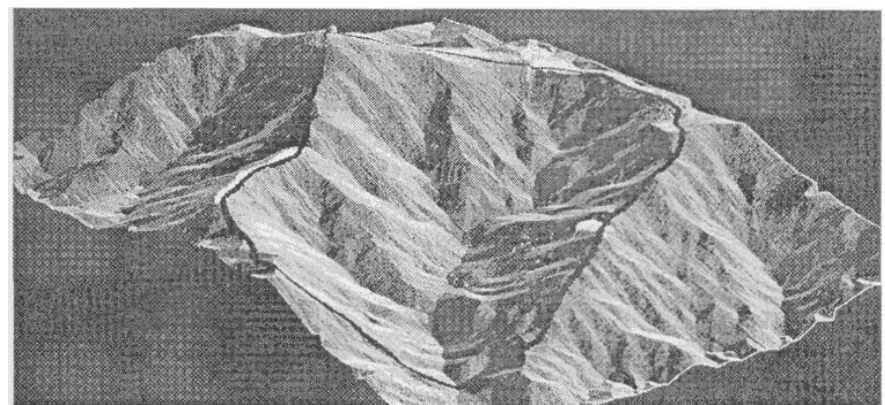

Figure 2: $3 \mathrm{D}$ View of Triantafilia.

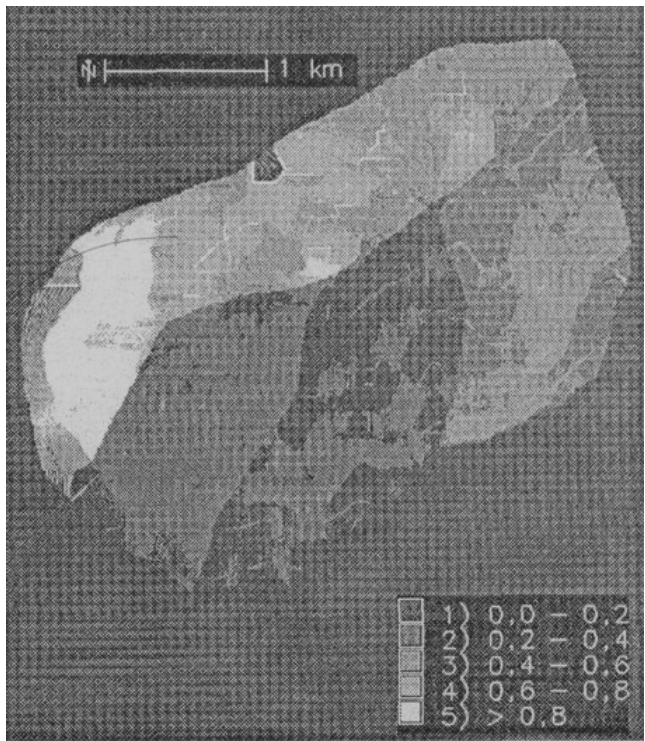

Figure 3: Grey-toned map of potential degradation with legendary classification (Triantafillia t.). 
Then the GRASS software tool r.mapcalc [13] was used; this is a program that allows users to manipulate, analyze, and create map data by performing mathematical calculations on raster map layers.

The under process and adjustment model by this way shows an improvement in the following points:

a. Precision of calculations: By the help of segmentation into cells we have a complete splitting of the basin in very small areas of $36-67 \mathrm{~m}^{2}$ which are worked out one by one as to the erosion coefficient, which is impossible without the G.I.S. process'. Besides, the most important American models such as ANSWERS, AGNPS, etc. run with such sort of splitting. In this adjustment model the watershed area slope is given "pointly" thus it is very important for the estimation of erodibility.

b. Ease at entering unlimited parameters: By entering the parameters in the form of raster maps in various layers, the participation process of many variables into the same model becomes much easier.

c. Convenience in processing the variable values: By applying the GRASS tool mapealc, any mathematical elaboration on the above mentioned raster maps is feasible resulting that the most complex combinations of parameter values become simple as to their calculation.

d. Appearance: 3D construction provided by the new model improves the appearance of the "real" picture of watersheds, depicting them as they are in nature and not as on the map.

\section{Research results}

The elaboration of the coefficients $\mathrm{x}, \mathrm{y},<\mathrm{p}$ and the other factors of the method come up the erosion $\mathrm{z}$ coefficients for each watershed. The final coefficient $\mathrm{z}$ of each watershed was the weighed result of partial coefficients $z$, from which each one represents the erosion coefficient of a group" of cells. It is evident that all cells of the same group have the same $z$. The groups for each watershed, depending on the case, were ranging from tens to several hundreds. Meanwhile, the size of the used analysis through the GRASS is extremely remarkable, considering that each group may include some tens of cells. In Table 2 the partial coefficients zx of the cells groups of Riganorema are quoted.

In addition, in Table 3 the values of the final $z$ estimation for all the watersheds of the sample but also the total respective annual sediment and debris yield $\mathrm{W}$, are quoted.

The analysis of the results gave the following findings:

The bigger annual degradation is displayed by the Riganorema torrent and the smallest one by the Triantafillia.

The first one has a geological base of silt-mixed marls and sandstones whereas the second one has pure granites. Also, the first one has relatively sparse vegetation of degraded coniferous forests and grasslands while the second one has extensive forest stands and shrubberies in good condition. Thus, the bigger average annual production of debris material of the first one in relation to the second is clearly explained. Finally, the other two watersheds, displaying 
intermediate values of degradation, have respective intermediate values $\%$ and y of the vegetation and geology coefficients as well.

Table 2: $\quad$ Partial coefficients $z$, of the cells groups of Riganorema.

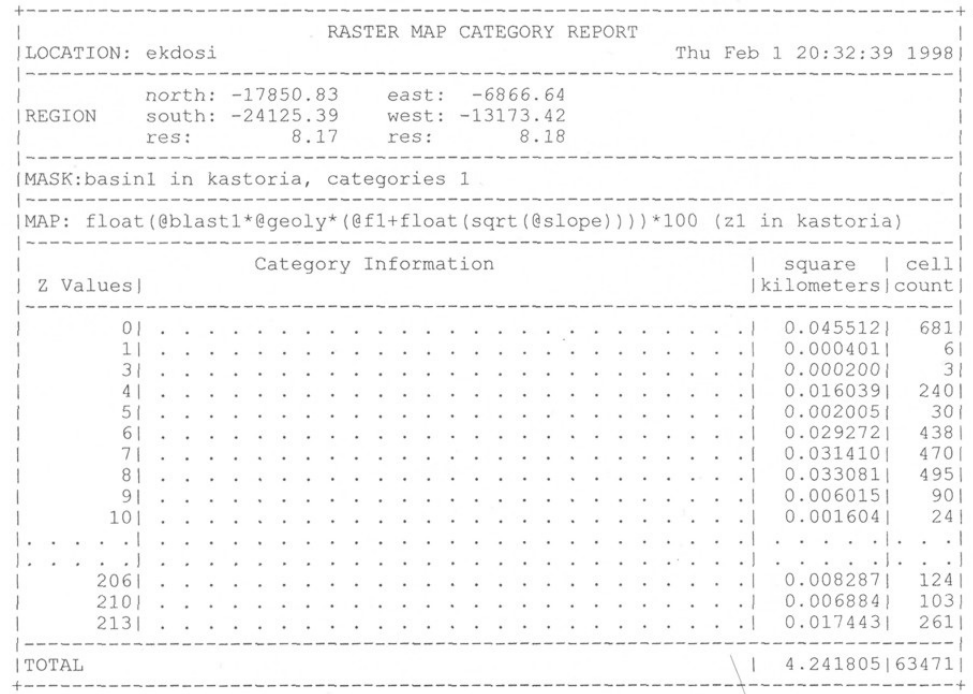

Table 3: $\quad$ Final $\mathrm{z}$ values and $\mathrm{W}$ values.

\begin{tabular}{|l|l|c|c|c|}
\hline \multicolumn{2}{|c|}{ Torrents } & \multirow{2}{*}{$\begin{array}{c}\text { Coefficient } \\
\mathrm{z}\end{array}$} & $\begin{array}{c}\text { Average annual } \\
\text { sediment and debris } \\
\left.\text { yield, W ( } \mathrm{m}^{3} / \text { year }\right)\end{array}$ & $\begin{array}{c}\text { Average } \\
\text { annual } \\
\text { degradation } \\
(\mathrm{mm})\end{array}$ \\
\hline 1 & Riganorrema & 0.78 & 15.82 & 1.57 \\
\hline 2 & Fotini & 0.66 & 5.484 & 1.22 \\
\hline 3 & Triantafillia & 0.75 & 6.823 & 0.75 \\
\hline
\end{tabular}

Map and legend study indicates that the areas with light chromatic tones are the ones with higher risk from erosion and leaching and which need immediate protection. In other words, we notice that degradation from watershed to watershed differs quite, and surely in all cases is bigger than the average degradation given by Kotoulas for the Greek inland and which equals to 0.67 $\mathrm{mm}$. Therefore, we realise that they are watersheds of mountainous character with a significant discharge of debris material. Finally, in order to have an even more integrated picture of the $\mathrm{z}$ distribution upon all watersheds of the sample, we drew some maps as follows:

For the construction of maps we classified the values of $Z$; into 5 categories, arising from the tables such table 2. This classification has applied a different colour of grey tone for each category. Thus, surfaces with the same colour tone 
corresponding to each particular category zi have arisen. In fact, by this way we had one more (but much more synoptically) grouping of $z$, so that to have a final result which is a coloured map of potential degradations with constant categorised annotated chromatology (figure 4).

\section{Protection system}

The protection system recommended in the present paperwork for the erodible areas, as mentioned earlier, is a mixed system of agro-plant-artificial works. The agro-plant-artificial works is a relatively old protection technique against erosion however specialised and with best results usually in the area of hillsides in respect to area of gullies.

The selection of species and number of works depend on the slope of hillsides or gullies as well as on the soil type and the aspect. So, the standardisation of these works is possible (Emmanouloudis [14]) according to the case, when we are aware of the above factors in an interference area. However, the elaboration of the Gavrilovic model through the GRASS, in addition to its other mentioned earlier advantages, provides higher possibility of having in each area the surface slopes along with the aspect map. Thus, in conjunction to the aforesaid standardisation, according to Emmanouloudis [14], we may suggest per $\mathrm{z}$ category the following agro-plant-artificial works:

\section{Area of hillsides}

\begin{tabular}{|l|l|}
\hline$Z_{0,6-0.8+}$ & $\begin{array}{l}\text { Construction of mosaic clusters } \\
\text { with very tolerant species }\end{array}$ \\
\hline$Z_{0,4-0,6}$ & Construction of envelopments \\
\hline
\end{tabular}

Area of micro gullies

\begin{tabular}{|l|l|}
\hline$Z_{0.8+}$ & Construction of picket fence belt \\
\hline$Z_{0,6-0.8}$ & Construction of envelopments belt \\
\hline$Z_{0,4-0,6}$ & Construction of clusters belt \\
\hline
\end{tabular}

\section{Conclusions}

Summarising all the above mentioned, we drew up the following conclusions:

For the quantitative estimation of mountainous watersheds degradation a new model was used. The contemplative model of Gavrilovic served as a startingpoint, which has been further stretched out by initiating appropriate adjustments by the use of the G.I.S. GRASS In the case of the four runoff basins, the average annual degradation has been calculated with a remarkably high precision due to this improved model. Actually, it is a combination of the Gavrilovic and the most 
known American definition model. Also, an attempt was made so that the "Balkan" parameters of the first one (which resembles the Greek torrential environment) and the American G.I.S. detailed techniques are blended. Four maps of potentional erosion came out after calculating degradation; their study, along with a standardised system of protection works, can provide an integrated protection system planning. What's more important, this improved model of estimation and the protection works system may be applied on any watershed.

\section{References}

[1] Line, D., Foster, M., "User's Manual for the watersheds GRASS - AGNPS modelling tool", N. Carolina State University, U.S.A., 1996.

[2] Beasly, D., Huggins, L., "ANSWERS User's Manual", Purdue University, U.S.A., 1991.

[3] Rydgren, B. ,"Soil erosion: its measurement, effects and prediction. Case study from the southern Lesotho lowlands", z.f.Geom. N.F. 40, 429-445, Dec. 1996, Uppsala., 1996.

[4] Terry, J.P., "Erosion pavement formation and slope process interactions in commercial forest plantations", n. Portugal, z.f.Geom. N.F. 40, 107 - 115, Marz 1996, Bunbury, 1996.

[5] Mitas, L., Mitasova, H., Brown, W., and Astley, M., "Interacting fields approach for evolving spatial phenomena : application to erosion simulation for optimized land use", National Center for Geog. Inf. and Analysis, C.A., U.S.A., 1996.

[6] Kotoulas, D., Diefthetisis Himarikon Revmaton , A.U.T., Thessaloniki., 1997.

[7] Gavrilovic, SI., "Inzenjcring o bujich im tokovima i eroziji", Beograd, 1972.

[8] Emmanouloudis, D., "Natural depositional landforms of the Greek torrents", Ph.D. Thesis, Dpt. of Forestry and Nat. Environment, A.U.T., Thessaloniki., 1990.

[9] Pintar. J., "Grenzen und Moglichkeiten der vorbeugung vor Unwetterkatastrophen im alpinen Raum", INTERPRAEVENT, Villach, AUSTRIA., 1972.

[10] Emmanouloudis. D., Filippidis, E., "Torrents basins Morphometric features calculation through 3-D models", Institute for education and Technology of Drama. Special Edition, 2001.

[11] Shapiro, M., Westerveld, J, "GRASS user's manual", U.S. Army Construction Engineering Research Laboratory, Champain, Illinois, U.S.A. ., 1993.

[12] Neidig, C.A., Gerdes, D., Kos, Ch., "GRASS 4.0 Map Digitizing Manual : v.digit", U.S. Army Construction Engineering Research Laboratory, Champain, Illinois, U.S.A., 1991. 
262 Geo-Environment and Landscape Evolution II

[13] Shapiro, M., Westerveld, J., "r.mapcalc. An algebra for G.I.S. and image processing", U.S. Army Construction Engineering Research Laboratory, Champain, Illinois, U.S.A. 1992.

[14] Emmanouloudis, D., "The contribution of watershed management to the integrated flood protection of the Athens basins", 2nd International Conference of C.N.W.R., Athens., 1994. 